\title{
SUBJECTIVE COMPLAINTS OF PEOPLE LIVING NEAR MOBILE PHONE BASE STATIONS IN POLAND
}

\section{ALICJA BORTKIEWICZ1 ${ }^{1}$, ELŻBIETA GADZICKA ${ }^{1}$, AGATA SZYJKOWSKA ${ }^{1}$, PIOTR POLITAŃSKI², PAWEŁ MAMROT'2, WIESŁAW SZYMCZAK ${ }^{3}$, and MAREK ZMYŚLONY²}

${ }^{1}$ Nofer Institute of Occupational Medicine, Łódź, Poland

Department of Work Physiology and Ergonomics

${ }^{2}$ Nofer Institute of Occupational Medicine, Łódź, Poland

Department of Radiological Protection

${ }^{3}$ University of Łódź, Łódź, Poland

Department of Psychological Research Methodology and Statistics

\begin{abstract}
Objectives: The aim of our study was to assess the health conditions and subjective symptoms of the inhabitants living in the base stations vicinity and to analyse the relationship between the complaints and level of exposure to electromagnetic fields (EMF). Materials and Methods: Our study was performed in housing estates located in five regions of Łódź. The electric field measurements were performed in the buildings located closest to the azimuth of the antennas. Respondents were selected by trained interviewers using an uniform procedure. The number of the households to be examined was set at a minimum of 420 . The questionnaire contained: demographic data, occupational and environmental exposure to EMF, health condition, subjective complaints. Results were adjusted for confounders (age, gender, EMF at the workplace and EMF emitted by household equipment) using multiple regression model. Results: 181 men and 319 women from 500 households were examined. Electric field above $0.8 \mathrm{~V} / \mathrm{m}$ was recorded in $12 \%$ of flats. There was no significant correlation between electric field strength and the distance of examined flats from the base stations. To make possible comparison with relevant literature, we analysed also the frequency of the reported symptoms vs. the distance. Headache was declared by $57 \%$ people, most frequently $(36.4 \%)$ living $100-150 \mathrm{~m}$ away from the base station compared to people living at longer distances $(\mathrm{p}=0.013) .24 .4 \%$ subjects, mostly living at a distance above $150 \mathrm{~m}$, declared impaired memory. Difference was statistically significant in comparison with people living at other distances $(p=0.004)$. Conclusions: The explanation why we did not find any correlation between the electric field strength and frequency of subjective symptoms but found a correlation between subjective symptoms and distance from base station needs further studies. Maybe new metrics of exposure assessment should be adopted for this purpose.
\end{abstract}

Key words:

Base stations, Electromagnetic fields, Health effects, Subjective symptoms

This study was supported by the National Committee for Scientific Research (KBN) in Poland Received: July 7, 2011. Accepted: November 22, 2011.

Address reprint request to A. Bortkiewicz, Department of Work Physiology and Ergonomics, Nofer Institute of Occupational Medicine, św. Teresy 8, 91-348 Łódź, Poland (e-mail:alab@bg.p.lodz.pl). 


\section{INTRODUCTION}

The rapid development of mobile phone systems has resulted in growing concern about possible adverse health effects of exposure to electromagnetic fields (EMF) emitted by those systems. While bioelectromagnetics experts are concerned primarily with possible adverse effects of the hand-held telephones (terminals), the general opinion seems to be considerably more concerned about the base stations. Data from mobile phone operators in Poland show that construction of almost half of the base stations was protested by the inhabitants of the houses located in the vicinity of those stations. Concern about health was stated to be the main reason of the protests. Those protests could be deemed reasonable only if research would confirm that the exposure levels experienced by those inhabitants may cause adverse health effects. Hypohtesizing about such possible adverse effects at the present state of our knowledge is encumbered with a high degree of uncertainty. Up to now, research on EMF health effects has been focused on acute exposures to relatively high-intensity fields for relatively short periods of time (usually a part of work shift). Exposure to base stations EMF is characterised by low EMF intensities and very long time ( $24 \mathrm{~h}$ /day for many years).

In Poland, research on base station EMF effects on health condition of the people living in the vicinity of those stations has never been performed, while worldwide such research is scarce. At present, results of 6 such studies, performed in France [1,2], Spain [3], Austria [4], Egypt [5] and Germany [6], are accessible. The protocol of all those studies was similar, i.e. those were questionnaire surveys of groups of ca. 100 to 500 people. In some of them, also psychological tests were performed but in rather small groups of participants $[4,5]$. In the French study, distance from the base station was used as the exposure index, while in the remaining studies EMF measurements were performed (power density was determined in the Austrian study, while electric field strength was measured in the Spanish study).

The aim of our study was to assess the health condition and subjective symptoms of the inhabitants living in the vicinity of the base stations and to analyse the relationship between the complaints and level of exposure.

\section{MATERIALS AND METHODS}

\section{EMF exposure}

Sector broadcasting antennas located on building's roofs are the major EMF sources of the telephone base stations. The distribution of power densities around the base station antennas depends chiefly on the distance from the antenna. According to literature data, maximum EMF intensities may be expected on the ground level at the horizontal distance of ca. $100 \mathrm{~m}$ from the typical antenna (53-61 dBm EIRP) placed ca. $30 \mathrm{~m}$ above ground level. At distances above $500 \mathrm{~m}$, EMF values are small [7-10]. Base station antennas are usually mounted ca. 20-40 $\mathrm{m}$ above the ground level so, in urban settings, due to high residential housing, EMF exposure may be higher than in non-urban areas. Other factors significantly affecting the intensity of EMF acting on humans include the direction of radiation and antenna inclination angle. A typical distribution of EMF around a base station is irregular, whereby exposure of people staying at the same distance from the antenna may considerably differ. Another factor causing that exposure of people located at the same distance from the base station may be different is that base station EMF is absorbed by the construction materials [11,12]. Thus, according to the general opinion of experts, human EMF exposures should not be based solely on the inhabitants' distance from the base station; instead, true EMF value should be determined. However, in the relevant literature, most of the studies were performed in relation to the distance. To make it possible to compare our results with 
relevant literature data, in our research, in addition to measurements of EMF in those flats we analysed the observed symptoms in relation to the distance from the base station.

Our study was performed in housing estates located in five regions of Łódź. The buildings were selected based on the results of the following analyses:

- transmitter output power (ranging from $8 \mathrm{~W}$ to $25 \mathrm{~W}$ ),

- antenna power gains (from $14 \mathrm{dBi}$ to $18 \mathrm{dBi}$ ),

- $\quad$ antenna mounting height (from $27 \mathrm{~m}$ to $40 \mathrm{~m}$ above the ground level),

- antenna radiation direction (azimuth),

- antenna inclination angle (from $0^{\circ}$ to $6^{\circ}$ ),

- distance from antenna (from $50 \mathrm{~m}$ to $500 \mathrm{~m}$ ),

- height of buildings (usually 4 to 11 floors high).

When analysing the relationship between the symptoms and the distance of the flat from the base station, the distance was determined from the housing estate plan. However, EMF intensity was correlated with the distance between the electrical centre of the antenna and the flat's window facing the base station.

To capture maximal irradiation conditions, the measurements were performed in the highest buildings located closest to the azimuth of the antennas radiating strongest EMF. A MEH-25 measuring set provided with an AS-1 probe developed at the Wrocław Technical University was used (frequency range $300 \mathrm{MHz}-3 \mathrm{GHz}$, measuring range:

- $\quad 0.8-3.2 \mathrm{~V} / \mathrm{m}$ with inaccuracy of EMF measurements in the free space $\pm 3 \mathrm{~dB}$ and $\pm 5 \mathrm{~dB}$ for measurements at $10 \mathrm{~cm}$ distance from primary and secondary radiation sources;

- $\quad 3.2-190 \mathrm{~V} / \mathrm{m}$ with inaccuracy of EMF measurements in the free space $10 \%$ and $\pm 3 \mathrm{~dB}$ for measurements at $10 \mathrm{~cm}$ distance from primary and secondary radiation sources).

Measurement results were assigned to examined subjects according to their address. All inhabitants of a given flat were assumed to be exposed to the same EMF. Considering the 24-h variability of base station loading, all measurements were performed at the same time of day and week.

Measurements of electric field strength (E) were performed with proper regard to current Polish standard procedures. Spot measurements were used. Three measurements were performed at 5-minute intervals, and the average was used as the result. The measurements were performed at the places where the inhabitants stayed most frequently and for longest time, i.e. above the sleeping places and at the middle of the rooms in which the inhabitants stayed during daytime. Mean value measured in all places was assumed to represent the value of the electric field emitted by mobile phone base stations to which a study person was exposed.

The inhabitants were not informed what kind of the environmental agents measurement was being carried out.

\section{Study group}

The total number of inhabitants living in the flats selected for the study was 1154 . The sampling frame of the test sample included all adult (18 yrs. of age and older) people living in the flats at the indicated addresses and present there at the time of the study. Respondents were selected using an uniform procedure by a specifically trained interviewer. After having received preliminary consent, the interviewer registered all adult persons available at the time of the interview into a special table (arranged according to age, starting from the oldest) and then the interviewer selected the respondent, counting according to the last digit of the interview number (which was the last digit of the number of flat in which the selection procedure was effected). All essential circumstances associated with respondent selection (including e.g., the causes of failure to take the interview with the selected person) were noted. Assessment of the frequency of the subjective symptoms was performed for all group 
of people involved in the interview study, i.e. for 500 people. All subjects gave their formal consent prior to inclusion to study. Before the onset of the examination, all procedures were fully explained to each participant. The protocol was approved by the Regional Biomedical Ethics Committee.

\section{Questionnaire}

The questionnaire comprises several groups of questions on:

- demographic data (age, gender, marital status, social status, educational level, living conditions, level of income);

- data on occupational and environmental exposure to power line- and radio-frequency fields (e.g., personal computers, microwave ovens, wireless phones, microwave alarms, household equipment, indoor transformer station etc);

- data on health condition determined from self-assessment and from diseases diagnosed earlier by physician and reported by the interviewed subject;

- subjective complaints, comprising e.g. nervous, circulatory, procreative, menopausal and sleep disorder symptoms.

The part of the questionnaire concerned with subjective complaints was developed in collaboration with the Centro de Investigacion, Hospital Universitario „LA FE” (Valencia, Spain), Institute of Environmental Health (Wien, Austria), and Institut National des Sciences Appliquees, Laboratoire de Biochimie-Pharmacologie (Villeurbanne, France). Questions referring to sleep disturbances were developed in consultation with experts from Sleep Disturbance Research Laboratory, Warsaw, Poland. The interviewed people were informed that the survey was intended to assess possible effects of environmental factors on inhabitants' health without being offered information which specific factors were concerned, to prevent possible respondents' bias.

\section{Statistical analysis}

The following tools were used to analyse the results:

- chi-square test of independence or exact Fisher test to compare frequency distributions (questionnaire survey or testing) of categories of variables characterising the exposure,

- one-way analysis of variance with multiple comparison tests to compare continuous-variables means between categories of variables characterising the exposure.

For assessing the incidence of the complaints, household was assumed to be the unit. In a demographic study performed in Łódź it has been found that a household includes on the average 3 people. Thus, a variance of proportion estimator is denoted by:

$$
\mathrm{D}^{2}=\frac{\sum_{\mathrm{r}=1}^{\mathrm{M}}\left(\pi_{\mathrm{r}}-\pi\right)^{2}}{(\mathrm{M}-1) \times \mathrm{m}} \times \frac{\mathrm{M}-\mathrm{m}}{\mathrm{M}}
$$

where:

- M - number of households in the study,

- $\mathrm{m}$ - number of random-selected households,

- $\quad \pi_{\mathrm{r}}(\mathrm{r}=1, \ldots, \mathrm{M})$ - sample proportion of elements with characteristic being considered,

- $\quad \pi$ - population proportion of elements with characteristic being considered.

Assuming assessment precision of $\Delta^{2}$, i.e. $\mathrm{D}^{2}=\Delta^{2}$ the formula:

$$
\mathrm{m}=\frac{\mathrm{M} \times \sum_{\mathrm{r}=1}^{\mathrm{M}}\left(\pi_{\mathrm{r}}-\pi\right)^{2}}{\sum_{\mathrm{r}=1}^{\mathrm{M}}\left(\pi_{\mathrm{r}}-\pi\right)^{2}+\Delta^{2} \times \mathrm{M} \times(\mathrm{M}-1)}
$$

enables assessment of the number of random-selected households required to ensure precision $\Delta$. From the results of the performed analyses, the number of the households to be examined was set at a minimum of 420 .

Results were adjusted for confounders (age, gender, EMF emitted by different sources at the workplace and household equipment) using multiple regression model. 


\section{RESULTS}

\section{Exposure assessment}

Figure 1 shows the results of measurements of the electric field strength performed to enable assessment of exposures to EMF radiated by cellular phone base station antennas - the incidence of various values of the electric field emitted by those antennas measured in different flats, at various distances between the flat and the base station.

The results of the measurements show that electric field above $0.8 \mathrm{~V} / \mathrm{m}$ (sensitivity of the measuring set) was recorded in 23 of 195 flats where electric field was measured (accounting for ca. 12\% of studied flats). Considering that flats chosen for determination of electric field included those for which, based on results of base station antenna EMF emission characteristics, EMF exposures were likely to be highest, it seems reasonable to expect that EMF with $\mathrm{E}$ values above $0.8 \mathrm{~V} / \mathrm{m}$ prevails in less than $10 \%$ of the flats located within the distance $50-500 \mathrm{~m}$ from the base station.

The measured values were lower than $3.2 \mathrm{~V} / \mathrm{m}$ (Figure 1). Thus, it is reasonable to conclude that EMF exceeding the admissible value specified by Polish standards, i.e. $7 \mathrm{~V} / \mathrm{m}$ were not present in any of the selected flats [13].

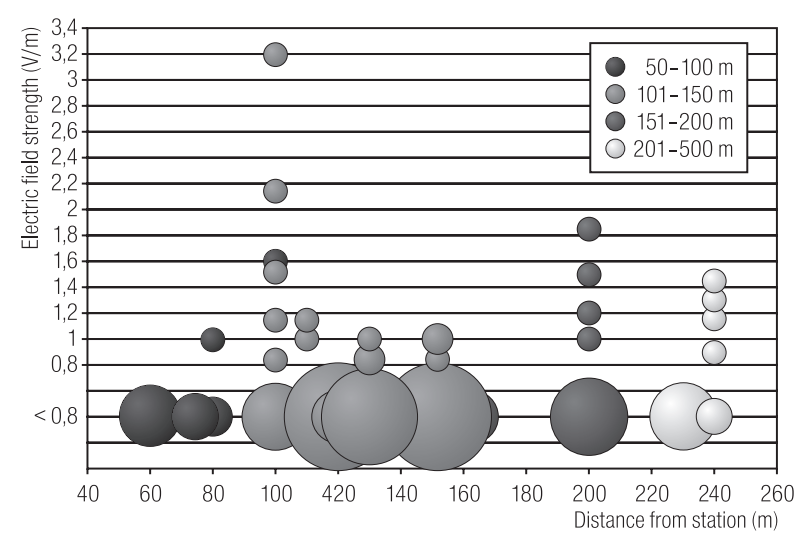

Fig. 1. Electric field strength in flats located at various distances from the base station. Circle surface is proportional to the number of points located at a specified distance from the base station at which the measured electric field values were the same.

\section{Results of questionnaire survey}

The study group was classified according to the distance from the base station. Four groups were established:

1. Group of people living at the distance of $50-100 \mathrm{~m}$ from the base station.

2. Group of people living at the distance of 101-150 m from the base station.

3. Group of people living at the distance of $151-200 \mathrm{~m}$ from the base station.

4. Group of people living at the distance of 201-500 $\mathrm{m}$ from the base station.

None of the persons in the study group lived at the distance shorter than $50 \mathrm{~m}$ from the base station.

The study group comprised 181 (36.2\%) men and 319 $(63.8 \%)$ women at the age of $48.7 \pm 17.0$. In the group of men, mean age was $46.2 \pm 29.0$ years. Mean number of people in a given household was 2 persons $(2.3 \pm 1.1)$, minimum 1 person, maximum 6 persons.

The interviewed persons usually assessed their health condition as rather good, $53.6 \%$, while only $14.5 \%$ declared that their health was very good. Rather poor health condition was reported by $24.2 \%$ respondents, and $7.7 \%$ said it was very poor. Our analysis of the relationship between subjective health assessment and the distance from the base station shows that poor and very poor health condition was declared most frequently by people living at a distance above $200 \mathrm{~m}$ from the base station (43.3\%). However, the differences between the groups were not statistically significant.

Headache was fairly frequent in the study group; it was declared by ca. $57 \%$ people. It is particularly worth noting that daily or almost daily headache was reported most frequently by people living 101-150 $\mathrm{m}$ away from the base station $(36.4 \%)$ compared to people inhabiting flats located at longer distances. The difference was statistically significant $(\mathrm{p}=0.013)$.

Impaired memory was declared in total by $24.4 \%$ subjects. Most of the memory problems were reported by 
people living at a distance above $150 \mathrm{~m}$ (group $3-25.2 \%$, group 4-26.9\%). The difference between the groups living close to the station (group $1-15 \%$, and group $2-14.7 \%$ ) and the groups living at a greater distance (groups 3 and 4 ) was statistically significant $(\mathrm{p}=0.004)$.

A tendency to experiencing depression was declared in total by $19 \%$ respondents. Of those, $23.3 \%$ and $21.3 \%$ lived at the shortest and the longest distance from the base station, respectively. On the other hand, among the inhabitants living 101-150 $\mathrm{m}$ and 151-200 $\mathrm{m}$ away, the proportion (12\% and $14 \%)$ was very similar. The difference was close to the border of statistical significance $(p=0.059)$.

Dermal changes were declared by $13.4 \%$ people; among those, most (18.2\%) were living 101-150 m away from the station $(\mathrm{p}=0.006)$.

For the remaining complaints, the differences between the groups living at varying distances from the base stations were not statistically significant.

Feeling of fatigue was reported by $63.6 \%$ of the respondents. The majority, $67 \%$ of those people lived over $200 \mathrm{~m}$ away from the station. Irritation appeared in $44 \%$ of the subject, but it was not dependent on the distance from the station.

Circulatory symptoms were declared by $35.8 \%$ people. Dyspnoea was reported by $18.6 \%$ subjects, palpitation $25.6 \%$, piercing pain in the region of the heart $15.6 \%$, anginous pain by $13.2 \%$. heartburn $4.7 \%$. No relationship was found to occur between the particular circulatory symptoms and the distance from base station.

Sleeping disorders were present in $32.8 \%$ subjects, $53 \%$ of these declared problems with falling asleep. In $58.5 \%$ subjects, sleep was periodically interrupted. Light sleep was declared by $17.1 \%$ people, while $26.8 \%$ complained of early waking. Feeling sleepy after awakening was present in $29.9 \%$ of the subjects. As much as $46 \%$ of the respondents associated those disorders with stress, problems at work and at home, and depression, while other causes were declared only by $1.8 \%$ of the people. Almost half $(43,6 \%)$ of the subjects experienced those disorders every day or almost every day, $30.7 \%$ several times a week. The disorders were experienced 2-3 times a month by $22.1 \%$ respondents and about once a week also by $22.1 \%$. Only $3.7 \%$ of the subjects with sleep disorders experienced them once a month. No significant differences were noted between study groups in the frequency of the reported sleep disorders.

Vertigo was present in $25 \%$ of the subjects, most frequently in those living 100-150 m away from the base station, representing $45 \%$ of all vertigo-affected subjects.

Mental discomfort was experienced by $22 \%$, while problems with concentration by $18.8 \%$ of the interviewed people. Vision disorders were reported by $19.4 \%$, and hearing problems by $10.4 \%$ of the subjects; also in this instance there were no statistically significant differences between groups depending on the distance from the base station. The least frequent complaints included loss of appetite (5.6\%) and nausea (3.6\%).

Data on reproductive health, both for women and men, were also analysed. It has been found that there were no significant differences between groups living at different distances from the base station. There was, however, a large number of problems associated with: menstruation disturbances (16\% women), conception (11\%), impaired libido (28\% women). Among the male subjects, reluctance to have sex was declared only by $14 \%$ of the respondents. Noise, dust, chemical pollution and other factors were also present in the environment of the examined subjects. Among the annoying factors present at the place of residence, noise was reported by as much as $34 \%$ of the subjects in spite that the buildings selected for the study were located in a residential district, away from heavy traffic. Complaints about excessive dust were received from $8.2 \%$ of the subjects, while other annoyances, including troublesome neighbours, dirt, traffic exhaust fumes, chemical pollutants were reported by $18.8 \%$ subjects. Out of those subjects, 9 people reported harmful influence of the base 
stations. Also in workplace setting, noise was quoted most frequently as the source of annoyance (17\% subjects). Excessive airborne dust was reported by $8 \%$, while other annoying factors, such as stress, smoking co-workers (passive smoking), work with computer, air conditioning, chemical pollution were reported by $7.4 \%$ of the respondents. It has been found that the frequency of those factors (environmental as well as occupational) does not differ significantly between the groups of study participants classified according to the distance from the base stations. In addition, frequency of use of EMF-generating domestic (cellular and other wireless phones, hair dryers, microwave ovens, electric shavers, floor heating systems) and workplace (electric power supply system, welders, radio frequency heaters, etc.) devices was also assessed. Effect of the workplace EMF sources was analysed only in the occupationally active people (213 subjects). It has been found that the study groups did not differ in the frequency of occurrence of factors specified above.

\section{DISCUSSION}

Up to date, no studies have been performed using objective methods for evaluation of health status in people living near mobile phone base stations. Those which have been performed were limited to questionnaire survey; they were often encumbered with the subjectivism-related error, and it was not possible to determine the underlying causes of the reported complaints; however, it would not be reasonable to neglect the results of those studies.

The analysis of our data shows that there is no significant correlation between electric field strength and the distance of examined flats from the base station (coefficient $\mathrm{R}^{2}$ for the applied regression models does not exceed 0.02). Therefore, exposure assessment based solely on the distance from the base station is insufficient. The differences in field strength noted between various flats located at the same distance from the base station may be due to different location towards the direction of the maximum radiation (both in terms of azimuth and declination). Thus, in order to assess the exposure, field intensities were measured in the flats occupied by examined subjects. Those measurements showed that, in the considerable majority of the flats (over 90\%), the exposure was lower than the sensitivity of the applied measurement devices. Values of electric field strength measured in our study are in good agreement with the literature data; usually they range from 0.2 to $1.37 \mathrm{~V} / \mathrm{m}[9,10,11,14]$. The higher values reported by Petersen [15] result probably from the location of the antenna close to the roof $(3 \mathrm{~m})$. In many papers reporting adverse effects resulting from close proximity to the base station, EMF exposure remains within the admissible range specified by standards developed by international protection organisations, for example ICNIRP [16]. They support the beliefs of some bodies that the standards fail to ensure sufficient protection to the general population [17]. However, many of those papers were encumbered with errors resulting from questionnaire design, different methods applied for the selection of study group and insufficiently precise assessment of EMF exposure. Besides, other EMF sources were often neglected [18]. In some of the studies, the results are not coherent, for example more health problems were noted at a shorter distance from the base station [19], while measured EMF intensity did not correlate with the frequency of the complains [6]. One of the hypotheses attempting to explain those differences says that the exposure measures used heretofore may be insufficient to determine the relationship between EMF exposure and health condition of the exposed people. It seems advisable to consider inclusion of other EMF exposure metrics, as in the case of studies on the effects of power line EMF on health [20], despite difficulties with dosimetric measurements of RF fields. Another hypothesis worth considering is that the observed health effects may be due to greater stress caused by subjects' awareness of close proximity to 
the base station [21]; this hypothesis, however, failed to be confirmed in our study, because only 9 subjects declared concerns about proximity to the base station.

Studies performed in Switzerland [22], France [2], Spain [3] and Austria [4] show that people living at the distance shorter than $300 \mathrm{~m}$ from the base station reported headache, sleep disturbances, irritability, mental discomfort and fatigue more frequently than those living at longer distances. In our studies, headache was reported also very frequently (by $57 \%$ of the subjects), significantly more frequently in people living 100-150 m away from the base station. Those results are in line with the results of other authors. In Switzerland, headache was declared by $40 \%$ of the subjects [22]. In France, Austria and Spain, headache was noted most frequently in people living 100, 200, and up to $150 \mathrm{~m}$ away, respectively, from the base station [2-4]. Santini et al. noted significant difference in the frequency of headache between women and men, which was not analysed in our study [1].

In the Swiss study, sleep disorders (60\% of the subjects) were the most frequent complaint, while in our study they were reported by $33 \%$ subjects and were less frequent than headache [22]. We have not detected significant differences between the groups classified according to the distance from the base station. In the French and Austrian studies, sleep disorders dominated among the subjects living 100-200 $\mathrm{m}$ away [2,4].

The feeling of mental discomfort reported in the Santini et al. study was most frequent in people living 100-200 m away from the base station; this feeling was reported also by $22 \%$ of our subjects, but the frequency of that complaint was not correlated with the distance from the base station [2]. In other studies, irritability was reported by people living up to $150 \mathrm{~m}$ away from the base station [2-4]. Problems with concentration were dependent on the distance from the base station in the subjects of the studies performed in other countries [2-4], while in our study such relationship was not observed. Abel-Rassooul noted neuropsychiatric problems and impaired cognitive performance in the inhabitants living less than $10 \mathrm{~m}$ away from the base station [5].

Among 500 subjects of our study, only 9 people (1.8\%) claimed that the base station located in the vicinity of their place of habitation was an annoying factor of their environment. This result clearly differs from that obtained in Switzerland, where as much as $74 \%$ of the study subjects claimed that the nearby base station was a source of hazard [22]. Our result seems to be more objective, because the interviewed people were asked to specify annoying factors by themselves without being offered a choice of specified options.

In our study, a large number of the reported problems were associated with: disturbed menstrual cycle, achieving pregnancy, lower libido (28\% of the study women). However, no association was noted between the distance of the flat from the base station and premature menopause in the women.

Cardiovascular diseases, including arterial hypertension (29.8\% people) and ischaemic heart disease (18.2\% of the people) were the dominant health problem of the study subjects. The proportion of people with arterial hypertension in the general population of Poland is similar (29\%).

\section{CONCLUSIONS}

The results of our study show that electromagnetic fields (EMF) prevailing in residential buildings located at distances 50-500 $\mathrm{m}$ from mobile phone base stations did not exceed the maximum admissible EMF values specified by relevant Polish regulations. EMF values exceeding $0.8 \mathrm{~V} / \mathrm{m}$ (the lower limit of the sensitivity of the measuring set) were recorded in a small proportion (less than $10 \%$ ) of the flats located near the base station. The analysis of our results did not reveal a correlation between the electric field strength and the distance from the base station. Thus, distance from the base station should not be 
used as an indicator of exposure instead of the field measurements. However, a single measurement of the maximum value does not seem to be sufficient. A comprehensive exposure assessment should be performed, similar to that applied in studies on exposures to the fields generated by electric power lines.

Results of questionnaire survey show the most frequent complaints were feeling of fatigue $(64 \%)$, headache $(57 \%)$, vertigo (25\%), irritation (44\%), disturbed sleep, memory and concentration $(33 \%, 24 \%$ and $19 \%$ respectively) as well as tendency to depression (19\%) and feeling of mental discomfort (22\%). Some of this symptoms correlated with the distance from base station. Further studies are required to explain why we did not find any correlation between the electric field strength and frequency of subjective symptoms, while we did find a correlation between subjective symptoms and distance from base station. Maybe new metrics of exposure assessment should be used for that purpose. Therefore, comprehensive studies on the relationship between EMF emitted by base stations and health status should be continued.

\section{REFERENCES}

1. Santini R, Santini P, Danze JM, Le Ruz P, Seigne M. Study of the health of people living in the vicinity of mobile phone base stations: I. Influences of distance and sex. Pathol Biol 2002;50:369-73.

2. Santini R, Santini P, Le Ruz P, Danze JM, Seigne M. Survey Study of People Living in the Vicinity of Cellular Phone Base Stations. Electromag Biol Med 2003;1:41-9.

3. Navarro EA, Segura J, Portoles M, Gomez-Peretta C. The Microwave syndrome: A preliminary study in Spain. Electromag Biol Med 2003;22:161-9.

4. Hutter HP, Moshamer H, Wallner P, Kundi M. Subjective symptoms, sleeping problems and cognitive performance in subjects living near mobile phone base stations. Occup Environ Med 2006;63:307-13.
5. Abdel-Rassoul G, El-Fateh OA, Salem MA, Michaele A, Farahat F, El-Batanomy M, et al. Neurobehavioral effects among inhabitants around mobile phone base stations. Neurotoxicology 2007;28:434-40.

6. Berg-Beckhoff G, Blettner M, Kowall B, Breckenkamp J, Schlehofer B, Schmiedel S, et al. Mobile phone base stations and adverse health effects: Phase 2 of a cross-sectional study with measured radio frequency electromagnetic fields. Occup Environ Med 2009;66:124-30.

7. Bergqvist U, Friedrich G, Hamnerius Y, Martens L, Neubauer G, Thuroczy G, et al. Mobile telecommunication base stations - exposure to electromagnetic fields. Report of a Short Term Mission. COST 244bis: 11th Workshop on Biomedical Applications of EMFs and Management Committee Meeting, 2000 Oct 7-8; Bled, Slovenia. p. 1-77 [cited 2001 May 10]. Available from URL:http://www.radio.fer/cost244.

8. Haumann T, Münzenberg U, Maes W, Sierck P, Kostarakis P, editors. HF-radiation levels of GSM cellular phone towers in residential areas. Proceedings of the Biological Effects of PEMs 2nd International Workshop, Electronics - Telecom and Applications Laboratory, Physics Department, University of Ioannima, Institute of Informatics and Telecommunications; 2002 Oct 7-11; Rhodos, Greece. Athens: N.C.S.R. Demokritos; 2002. p. 327-33.

9. Mantiply ED, Pohl KR, Poppell SW, Murphy JA. Summary of measured radiofrequency electric and magnetic fields $(10 \mathrm{kHz}$ to $30 \mathrm{GHz})$ in the general and work environment. Bioelectromagnetics 1997;18:563-77.

10. Petersen RC, Testagrossa PA. Radio-frequency electromagnetic fields associated with cellular-radio cell-site antennas. Bioelectromagnetics 1992;13:527-42.

11. Mann SM, Cooper TG, Allen SG, Blackwell RP, Lowe AJ Exposure to radio waves near mobile phone base stations [report]. Natl Radiol Protec Board 2000;NRPB-R321 (UK).

12. Parsons JD. The Mobile Phone Propagation Channel. New York: Wiley and Sons; 1992.

13. Ordinance of the Ministry of Environmental Protection, Republic of Poland, October 30, 2003. J Law, 2003 No.192, pos. 18. 
14. Thansandote A, Gajda GB, Lecuyer DW. Radiofrequency radiation in five Vancouver schools: exposure standards not exceeded. Can Med Assoc J 1999;160:1311-2.

15. Petersen RC, Fahly-Elwood AK. Wireless telecommunications: Technology and RF safety issues. In: Hardy KA, Meltz ML, editors. Non-Ionizing Radiation: An Overview of the Physics and biology. Madison (WI): Medical Physics Publishing; 1997. p. 197-226.

16. ICNIRP. Guidelines for Limiting Exposure to Time-Varying Electric, Magnetic, and Electromagnetic Fields (up to $300 \mathrm{GHz}$ ). Health Phys 1998;74(4):494-522.

17. Hardell L, Sage C. Biological effects from electromagnetic field exposure and public exposure standards. Biomed Pharmacother 2008;62:104-9.

18. Neubauer G, Feychting M, Hamnerius Y, Kheifets L, Kuster N, Ruiz I, et al. Feasibility of future epidemiological studies on possible health effects of mobile phone base stations. Bioelectromagnetics 2007;28:224-30.
19. Blettner M, Schlehofer B, Breckenkamp J, Kowall B, Schmiedel S, Reis U, et al. Mobile phone base stations and adverse health effects: Phase 1 of a population-based, cross-sectional study in Germany. Occup Environ Med 2009;66:118-23 [in German].

20. Portier ChJ, Wolfe MS. Assessment of health effects from exposure to power-line frequency electric and magnetic fields. Working Group Report. NIEHS Working Group Report. NIH Publication No. 98-3981. Research Triangle Park (NC): NIEHS; 1998.

21. Röösli M. Radiofrequency electromagnetic field exposure and non-specific symptoms of ill health: A systematic review. Environ Res 2008;107:277-87.

22. Moser M, Röösli M. Epidemiological Studies on Mobile Phone base Stations and Health. Possible Biological Outcomes and Study Designs. Cost 281: Workshop on Mobile Phone base Stations and Health, 2003 May 15-16; Dublin, Ireland [cited 2003 Aug 15]. Available from URL:http:// www.radio.fer/cost281.

This work is available in Open Access model and licensed under a Creative Commons Attribution-NonCommercial 3.0 Poland License - http://creativecommons.org/ licenses/by-nc/3.0/pl/deed.en. 